Data de recebimento do artigo: 8-6-2017

Data de aceite do artigo: $17-1-2018$

\title{
Construção de um modelo de avaliação de desempenho: estudo de caso em uma empresa de pequeno porte da construção civil
}

\author{
Ana Paula de Archer de Arruda Borges \\ Professora da Faculdade Borges e Mendonça. Mestre em Ciências Contábeis pela UFSC. \\ E-mail: anaborges00@ hotmail.com (Brasil) \\ Gabriel Nilson Coelho \\ Mestrando em Ciências Contábeis na UFSC. E-mail: gn.coelho@hotmail.com (Brasil) \\ Sérgio Murilo Petri \\ Professor na Universidade Federal de Santa Catarina. Doutor em Engenharia de Produção pela UFSC. \\ E-mail: smpetri@gmail.com (Brasil)
}

\section{RESUMO}

A busca por vantagens competitivas em um cenário que passa por constantes mudanças como o da indústria da construção civil é uma necessidade presente. $\mathrm{O}$ objetivo deste estudo é construir um modelo de avaliação de desempenho para uma empresa de pequeno porte que atua nesse setor. A pesquisa é classificada como um estudo de caso em forma de pesquisa-ação, qualitativa, descritiva e aplicada. Foi elaborado o mapa estratégico da empresa baseado nas perspectivas do Balanced Scorecard. Para cada perspectiva da metodologia, foram identificados os indicadores a serem mensurados, a situação atual, as metas e um conjunto de iniciativas que propiciarão o atingimento das metas. Entende-se que a proposta irá reformular as atitudes dos membros da empresa, de forma que as atividades, as responsabilidades, e principalmente as estratégias sejam evidenciadas com maior clareza fazendo com que os gestores reflitam sobre o negócio de maneira organizada e sistêmica. Esta pesquisa se diferencia dos trabalhos similares por estudar uma empresa de pequeno porte, ramo pouco tratado na literatura, e abordar o assunto de maneira completa, ou seja, iniciando pelas estratégias, apresentando os indicadores, a situação atual, propondo metas e por fim sugerindo iniciativas.

Palavras-chave: Avaliação de desempenho. Construção Civil. Balanced Scorecard. Pequena Empresa. 


\title{
Construction of a performance evaluation model: case study in a small business company of civil construction
}

\begin{abstract}
The search for competitive advantages in a scenario that is constantly in economic, political, technological and environmental change is a present need for these organizations. The aim of this study is to propose a performance evaluation model for a small business in the construction industry. The study is an action research, classified as qualitative, descriptive, and applied. The strategic map of the company is using the perspectives of the Balanced Scorecard management tool. Then for each perspective of the methodology, the indicators to be measured have been identified, as well as the current situation and a set of initiatives that will provide the goals achievement. It is understood that the proposal will reshape the enterprise members' attitudes, so that activities, responsibilities, and especially the strategy are highlighted more clearly making managers think about the business in an organized and systematic way. This research differs from similar work once it is focused on studying a small business, which is not usual in the literature, and approaching the subject completely, starting with the strategies, and also presenting the indicators, the current situation, proposing goals and finally suggesting initiatives.
\end{abstract}

Keywords: Performance Evaluation. Construction Industry. Balanced Scorecard. Small Company.

\section{Como referenciar em APA:}

Borges, A. P. A. A., Coelho, G. N., Petri, S. M. (2018). Construção de um modelo de avaliação de desempenho: estudo de caso em uma empresa de pequeno porte da construção civil. R.G.Secr.,GESEC, 9(3).

\section{Como referenciar em ABNT:}

BORGES, A. P. A. A.; COELhO, G. N.; PETRI, S. M. Construção de um modelo de avaliação de desempenho: estudo de caso em uma empresa de pequeno porte da construção civil. R.G.Secr.,GESEC, v. 9, n. 3, Dez. 2018.
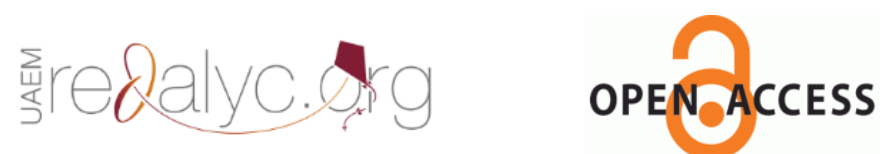


\section{Introdução}

No Brasil, de acordo com dados da CBIC, Câmara Brasileira da Indústria da Construção, baseados na pesquisa do IBGE, o crescimento no setor vinha ocorrendo acima do PIB Brasileiro desde 2010 e apesar da desaceleração nos anos de 2013 e 2014, o setor continua apresentando significativa relevância para a economia do país. Os números demonstram, portanto, um segmento que necessita de ser tratado com atenção e cuidado em função da capacidade que ele tem em impulsionar a economia nacional.

Para Teixeira e Carvalho (2011), a construção civil tem um papel fundamental nos programas de investimento e no novo ciclo de crescimento do País, pelas peculiaridades de sua cadeia produtiva, baixo efeito de importação e elevados efeitos multiplicadores sobre a economia, a renda, o emprego e tributos. O mesmo autor completa que o setor é representado em sua grande maioria pelas micro e pequenas empresas e uma forma de incentivar o crescimento dessas indústrias é a concessão de créditos, incentivos e benefícios por parte do governo que podem ser compensados pelo efeito multiplicador de tributos gerados pelo setor.

Segundo a Relação Anual de Informações Sociais (RAIS), do Ministério do Trabalho e Emprego (MTE), aproximadamente 79\% do total dos estabelecimentos ativos na construção civil são representados por empresas com até nove empregados. O grupo das empresas que possuem entre 10 e 99 empregados representam 19\%, seguido dos $2 \%$ das empresas com mais de 100 empregados. Apesar dos números significativos, na maioria das vezes, as grandes empresas são dominadoras desse mercado, impedindo o crescimento e destaque das micro, pequenas e médias organizações. Dessa forma, cabe às pequenas e médias empresas (PMEs) reverem seus processos e produtos de maneira que possam continuar competindo.

Sendo assim, existe a necessidade de as pequenas e médias empresas do ramo da construção civil aperfeiçoarem seu sistema de gestão visando maior desempenho com objetivo de contribuir com a competitividade e a busca constante por melhores resultados. Uma das maneiras de garantir a agilidade na tomada de decisão é aplicar as estratégias da organização de forma alinhada e focada.

Implantar um sistema de avaliação de desempenho para as pequenas empresas da construção civil pode ser um caminho estratégico frente à situação relatada. Entretanto, apesar do crescente interesse sobre a gestão do desempenho, muitas ainda são as dificuldades em avaliar o desempenho das organizações. 
Diversas são as ferramentas de gestão que podem auxiliar na avaliação e análise de resultados e desempenho. Kaplan e Norton (1997), dois pesquisadores de Harvard, desenvolveram um sistema de avaliação de desempenho, o Balanced Scorecard (BSC), como uma ferramenta que se propõe a traduzir a missão e a estratégia da organização num conjunto abrangente de medidas de desempenho que sirvam de base para um sistema de medição e gestão estratégica. Com o passar do tempo, de acordo com Costa (2006), o BSC mostrou-se um instrumento útil para traduzir a estratégia da empresa em objetivos específicos mensuráveis, tanto os de curto quanto os de longo prazo. Diante do exposto, surge o seguinte problema de pesquisa: Como avaliar o desempenho de uma instituição privada de pequeno porte do ramo da construção civil?

Com o propósito de responder à pergunta da pesquisa, o objetivo deste estudo é construir um modelo de avaliação de desempenho para uma empresa de pequeno porte do ramo da construção civil. Para tanto, faz-se necessário elaborar o mapa estratégico da empresa, definir os indicadores a serem mensurados, identificar a situação atual da instituição para definição de metas, e propor um conjunto de iniciativas para aperfeiçoar o desempenho da organização.

Esta pesquisa se justifica por estudar um setor que representa significativo impacto para a economia mundial e principalmente nacional. Além disso, o objeto em questão traz uma proposta pouco estudada na literatura, visto que está direcionada para organizações de pequeno porte, parcela predominante dos estabelecimentos de construção civil no país atualmente. Nos estudos que tratam do tema não foi constatada uma unanimidade em relação aos indicadores de análise, existindo uma variedade de indicadores relacionados às caraterísticas das empresas estudadas.

Dessa forma, a necessidade em fortalecer estratégias que auxiliem as pequenas empresas no processo de gestão e controle, atrelado às particularidades do setor da construção civil, originou a escolha do tema desta pesquisa. Desenvolver uma ferramenta que ajude na capacidade mensurar a performance dessas organizações poderá auxiliar os pequenos empresários a avaliarem melhor suas estratégias e o desempenho de suas organizações, contribuindo para melhores resultados e a permanência no mercado.

Além disso, as lacunas encontradas nos estudos relacionados ao tema, como a dificuldade de identificar o que medir e como medir o desempenho das organizações, são aqui 
desenvolvidas e exploradas detalhadamente com o propósito de esclarecer o que ainda é apresentado de forma obscura na literatura.

\section{Referencial Teórico}

Esta seção abordará a fundamentação teórica necessária para o desenvolvimento deste estudo. Para tanto são caracterizadas as empresas da construção civil, são definidos conceitos da área de avaliação de desempenho e da ferramenta Balanced Scorecard.

\section{Características da construção civil}

Descrever o quadro geral da construção civil implica uma tarefa multifacetada, pois este é um setor extremamente heterogêneo. Seja pela abrangência de atividades, seja pela tipologia das empresas, seja pelas tecnologias e qualificação de pessoal, ou ainda pela sua dispersão geográfica (ABDI, 2009, p.14).

$\mathrm{Na}$ tentativa de descrever as peculiaridades dessas organizações, Meseguer (1991), define que o setor pode ser caracterizado da seguinte maneira: 1) a construção é uma indústria de caráter nômade, com produtos únicos e não seriados; 2) é uma indústria muito tradicional, com grande inércia às alterações; 3) utiliza mão de obra intensiva e pouco qualificada, sendo que o emprego dessas pessoas tem caráter eventual e suas possibilidades de promoção são escassas, o que gera baixa motivação no trabalho; 4) a construção, de maneira geral, realiza seus trabalhos a céu aberto, gerando grande dependência dos fatores climáticos; 5) o produto é único, ou quase único, na vida do cliente final; 6) são empregadas especificações complexas e muitas vezes confusas; 7) as responsabilidades são dispersas e pouco definidas dentro da empresa; 8) o grau de precisão com que se trabalha na construção é, em geral, menor do que em outras indústrias, por exemplo, parâmetros relativos ao orçamento, prazo, conformidade etc.

Além disso, para Yamauchi (2003), enquanto as práticas construtivas tendem a se sofisticar, muitas técnicas utilizadas na construção civil ainda são realizadas de maneira artesanal, rudimentar e improvisadas. Tais hábitos caracterizam também o tipo de mão de obra peculiar a esse setor e, na maioria das vezes, selecionada sem critérios definidos de contratação, treinamento e muitas vezes realizados informalmente. Dessa forma, o setor passa 
a ser um dos principais geradores de empregos, com capacidade de absorção de grande contingente de mão de obra migratória e não especializada.

Moraes (2009) complementa a definição das características do setor da construção civil citando um estudo realizado pelo Sebrae-MG (2005) que aponta algumas particularidades: 1) ser altamente intensiva na geração de emprego, predominando a utilização de mão de obra de baixa qualificação, cabendo ao emprego formal pequena participação no total de trabalhadores ocupados pelo setor; 2) sua demanda apresenta forte dependência da evolução da renda interna e das condições creditícias; 3) possui reduzido coeficiente de importação, com elevada utilização de matérias-primas nacionais; 4) níveis de produtividade e competitividade bastante aquém do padrão existente nos países desenvolvidos, especialmente nos aspectos tecnológicos e de gestão, refletindo a existência de inúmeras ineficiências produtivas no setor; 5) existência de problemas diversos quanto à padronização e ao cumprimento de normas técnicas, observando-se elevados percentuais de não conformidade técnica dos materiais e componentes da construção civil habitacional.

Apesar de toda complexidade do setor, no Brasil, este tipo de indústria vem crescendo significativamente a cada ano. Segundo Breitbach (2009), a indústria da construção civil vem apresentando um excelente desempenho nos últimos anos, que pode ser apontado como a retomada de crescimento. Tal crescimento é sustentado principalmente pela atuação estimuladora e asseguradora do Governo Federal.

Ao descrever as características das empresas da construção civil, é preciso destacar as pequenas empresas deste setor. Tal destaque é necessário em função da representatividade que esse grupo possui no mercado e consequentemente a capacidade de produção, geração de empregos e contribuição para economia.

Frente às características relatadas e das particularidades e complexidades do setor, fica evidente a necessidade de se criar estratégias que garantam a essas empresas condições para a tomada de decisão e assim o atingimento de melhores resultados. Para tanto, diversas estratégias são seguidas com o objetivo de melhorar os processos organizacionais, aumentar o valor percebido pelos clientes diante dos produtos e serviços oferecidos, e aumentar a lucratividade.

\section{Avaliação de desempenho}

A competitividade e a rapidez com que as informações circulam nos dias atuais exigem que as organizações tenham controle e segurança para a tomada de decisão. A segurança 
citada pode estar na certeza de que as metas estão sendo alcançadas e que o planejamento da empresa está sendo concretizado a cada dia, ou seja, o desempenho da organização está de acordo com os objetivos e estratégias por ela traçados. Segundo Petri (2005, p. 38), “a continuidade competitiva das organizações reside na capacidade de seus executivos e da organização como um todo em gerar conhecimentos e utilizá-los, sistematicamente, para auxiliá-los no processo decisório". Para Galvão, Corrêa e Alves (2011), é necessário planejamento e controle do negócio para tomar decisões em um ambiente competitivo e de forte pressão. Todos os setores da organização devem responder, com agilidade e flexibilidade, ao processo de comunicação e tomada de decisão. Porém o fato de a empresa interagir constantemente com o ambiente a torna muito dinâmica e, portanto, essa postura das organizações muitas vezes não é uma tarefa fácil.

Para Costa (2003), por meio do processo de avaliação de desempenho é possível identificar as capacidades da organização e os níveis de desempenho esperados, tanto dos processos quanto do sistema organizacional. A autora cita algumas vantagens geradas pelo processo de avaliação de desempenho como a melhoria contínua dos processos, revisão de metas, acompanhamento de resultados, feedback, motivação, geração de informações preventivas e acompanhamento da estratégia

Existem diversas ferramentas na literatura que auxiliam a gestão e a medição de desempenho. A respeito destes instrumentos de gestão, Rigby e Bilodeau (2013) afirmam que todos carregam um conjunto de pontos fortes e fracos, e que o êxito na sua aplicação requer o entendimento de todos os efeitos (inclusive colaterais) de cada uma. Os autores apresentaram em seu estudo um ranking, referente o ano de 2013, das ferramentas de gestão mais utilizadas. De acordo com os resultados, é possível destacar o Balanced Scorecard que ocupa a quinta posição no ranking mundial e se apresenta em primeiro lugar na Europa.

Kaplan e Norton (1997) defendem que as empresas devem utilizar o Balanced Scorecard, pois a ferramenta preserva os indicadores financeiros como a síntese final do desempenho gerencial e organizacional, mas incorpora um conjunto de medidas mais genérico e integrado que vincula o desempenho sob a ótica dos clientes, processos internos, funcionários e sistemas ao sucesso financeiro a longo prazo. Dessa forma, torna-se uma ferramenta completa que traduz a visão e a estratégia da empresa num conjunto coerente de medidas de desempenho. 


\section{Balanced Scorecard}

A abordagem do Balanced Scorecard foi proposta por Robert Kaplan e David Norton, em artigo publicado na Harvard Business Review, de 1992. Segundo os autores, os modelos de gestão tradicionalmente utilizados pelas corporações estão atrelados a indicadores da contabilidade financeira, que analisam apenas os ativos tangíveis e refletem basicamente os resultados de curto prazo obtidos (Kaplan \& Norton, 1997). Assim, os autores propõem um modelo de gestão contemplando também indicadores não financeiros, possibilitando a avaliação dos ativos intangíveis tais como: relacionamento com clientes, processos internos, tecnologia da informação, capacidade e motivação dos colaboradores. Segundo Kraemer (2009), ele não representa substituição e muito menos pretende eliminar os indicadores financeiros tradicionais, a intenção é criar novas perspectivas que auxiliem a identificação dos fatores de crescimento que irão criar valor econômico a longo prazo.

O Balanced Scorecard é um sistema de gestão de desempenho que tem como foco a visão da empresa e as estratégias necessárias para atingi-la. Para tal, a avaliação do desempenho organizacional está desdobrada em quatro perspectivas de acordo com Kaplan e Norton (1997): 1) perspectiva financeira: avaliação da estratégia de crescimento, rentabilidade e risco sobre a visão dos acionistas da organização. 2) perspectiva dos clientes (stakeholders): avaliação da criação de valor e diferenciação, sob a visão do cliente; 3) perspectiva dos processos internos: avaliação dos processos de negócio que criam satisfação para os clientes e acionistas; 4) perspectiva de aprendizado e crescimento: avaliação de aspectos relativos ao desenvolvimento de um clima propício à mudança organizacional, à inovação e ao crescimento. Enquanto as perspectivas financeira e clientes descrevem os resultados desejados pela organização, os processos internos mostram como esses resultados são construídos, apoiados por atividades da perspectiva de aprendizado e crescimento.

De acordo com Kaplan e Norton (2001), o alinhamento dos objetivos nessas quatro perspectivas é a chave para a criação de valor pela manutenção do foco da empresa em estratégias consistentes e orientadas pela visão da organização.

No desenvolvimento de uma estrutura de causa para o efeito dos objetivos estratégicos, Kaplan e Norton criaram uma ferramenta denominada "Mapa Estratégico" visando traduzir as estratégias em termos operacionais. O mapa estratégico é uma representação visual da lógica 
da estratégia de uma organização, em que são conectados indicadores de desempenho aos objetivos estratégicos traçados.

De acordo com Costa, A. P. (2006), as quatro perspectivas apresentadas são utilizadas como base para a elaboração do Mapa Estratégico que tem como finalidade decodificar os complexos processos de escolha frente aos quais os gestores e todos os níveis são expostos diariamente. O mapa estratégico é o meio pelo qual se operacionaliza a vinculação do planejamento estratégico e o planejamento operacional. A autora complementa que o mapa é composto pelos objetivos estratégicos, medidas, metas e ações. A medida escolhida deve expressar adequadamente a magnitude do fenômeno que se deseja captar. Além disso, é necessário existir um elemento avaliador, para se comparar o desempenho medido com uma referência (metas). As metas devem expressar o nível de desempenho esperado com o qual o desempenho real deve ser comparado para ser avaliado. Por fim, é preciso existir um executor, substanciado nas ações que a empresa definirá para alcançar o resultado esperado.

Dessa forma Kaplan e Norton (2000) definem cinco princípios para a implantação do BSC: 1) traduzir a estratégia em termos operacionais; 2) alinhar a organização à estratégia; 3) tornar a estratégia responsabilidade de todos; 4) tornar a estratégia um processo contínuo; 5) mobilizar mudanças mediante liderança executiva.

Apesar da existência de uma metodologia para auxiliar a implantação dessa ferramenta, Costa, A.P. (2006) reforça que é preciso considerar uma série de cuidados no momento em que a organização decidir implantar o BSC. Entre eles é possível citar o perfil adequado da organização e dos dirigentes, a importância de não subestimar a complexidade das tarefas, definir previamente e com clareza a estratégia da corporação, garantir o comprometimento da alta administração e gestores, não utilizar um projeto padronizado, não exagerar na complexidade buscando a perfeição, ouvir as unidades de negócios, entre outros.

\section{Estudos similares}

Com o objetivo de compor um banco de estudos internacionais relacionados ao assunto, permitindo a identificação de artigos relevantes que geram conhecimento e dão suporte ao tema, foram encontrados 15 trabalhos similares por meio do instrumento de pesquisa ProKnow-C (desenvolvido pela Universidade Federal de Santa Catarina). O Quadro 1 
Construção de um modelo de avaliação de desempenho: estudo de caso em uma empresa de pequeno porte da construção civil

apresenta a lista final de estudos relacionados ao tema assim como os objetivos de cada trabalho.

Quadro 1 - Artigos selecionados para compor o portfólio bibliográfico internacional.

\begin{tabular}{|c|c|c|}
\hline AUTORES & TÍTULOS & OBJETIVO \\
\hline $\begin{array}{l}\text { M. Kagioglou, R. } \\
\text { Cooper and G. } \\
\text { Aouad }\end{array}$ & $\begin{array}{l}\text { Performance management in construction: a } \\
\text { conceptual framework }\end{array}$ & $\begin{array}{l}\text { Apresentação de quadro conceitual } \\
\text { integrando principais temas da Avaliação } \\
\text { de Desempenho. }\end{array}$ \\
\hline $\begin{array}{l}\text { H. A. Bassioni, A. } \\
\text { D. F. Price and T. } \\
\text { M. Hassan }\end{array}$ & Performance measurement in construction & $\begin{array}{l}\text { Analisar o desempenho dos quadros de } \\
\text { medição e suas aplicações nas empresas } \\
\text { de construção do Reino Unido. }\end{array}$ \\
\hline $\begin{array}{l}\text { P. E. D. Love and } \\
\text { G. D. Holt }\end{array}$ & $\begin{array}{l}\text { Construction business performance } \\
\text { measurement: the SPM alternative }\end{array}$ & $\begin{array}{l}\text { Apresentar os motivos e a necessidade de } \\
\text { avaliar o desempenho das empresas de } \\
\text { construção civil. }\end{array}$ \\
\hline $\begin{array}{l}\text { D. B. Costa, C. T. } \\
\text { Formoso, M. } \\
\text { Kagioglou, L. F. } \\
\text { Alarcon and C. H. } \\
\text { Caldas } \\
\end{array}$ & $\begin{array}{l}\text { Benchmarking initiatives in the construction } \\
\text { industry: lessons learned and improvement } \\
\text { opportunities }\end{array}$ & $\begin{array}{l}\text { Discutir casos práticos realizados no } \\
\text { Brasil, Chile, EUA e Reino Unido. }\end{array}$ \\
\hline $\begin{array}{l}\text { Ramirez, } \\
\text { R.R.,Alarcon,L.F. } \\
\text { C.,Knights,P., }\end{array}$ & $\begin{array}{l}\text { Benchmarking system for evaluating } \\
\text { management practices in the construction } \\
\text { industry }\end{array}$ & $\begin{array}{l}\text { Estudar a Avaliação de Desempenho em } \\
13 \text { empresas chilenas da construção civil }\end{array}$ \\
\hline $\begin{array}{l}\text { M. S. El-Mashaleh, } \\
\text { R. E. Minchin and } \\
\text { W. J. O'Brien } \\
\end{array}$ & $\begin{array}{l}\text { Management of construction firm } \\
\text { performance using benchmarking }\end{array}$ & $\begin{array}{l}\text { Apresentar críticas e vantagens do } \\
\text { benchmarking e proposta de um novo } \\
\text { modelo }\end{array}$ \\
\hline $\begin{array}{l}\text { Cheah, C. Y. J., } \\
\text { Garvin, M. J., and } \\
\text { Miller, J. B. }\end{array}$ & $\begin{array}{l}\text { Empirical study of strategic performance of } \\
\text { global construction firms. }\end{array}$ & $\begin{array}{l}\text { Identificar tendências ou fatores que } \\
\text { afetam o desempenho, a fim de inferir } \\
\text { aspectos importantes da gestão } \\
\text { estratégica. }\end{array}$ \\
\hline $\begin{array}{l}\text { I. Yu, K. Kim, Y. } \\
\text { Jung and S. Chin }\end{array}$ & $\begin{array}{l}\text { Comparable performance measurement } \\
\text { system for construction companies }\end{array}$ & $\begin{array}{l}\text { Proposta de um novo modelo de } \\
\text { Avaliação de Desempenho. }\end{array}$ \\
\hline $\begin{array}{l}\text { H. S. Robinson, C. } \\
\text { J. Anumba, P. M. } \\
\text { Carrillo and A. M. } \\
\text { Al-Ghassani }\end{array}$ & $\begin{array}{l}\text { Business performance measurement practices } \\
\text { in construction engineering organizations }\end{array}$ & $\begin{array}{l}\text { Desenvolve uma proposta de iniciativas } \\
\text { para realizar a Avaliação de Desempenho. }\end{array}$ \\
\hline $\begin{array}{l}\text { S. Nudurupati, T. } \\
\text { Arshad and T. } \\
\text { Tumer } \\
\end{array}$ & $\begin{array}{l}\text { Performance measurement in the } \\
\text { construction industry: an action case } \\
\text { investigating manufacturing methodologies }\end{array}$ & $\begin{array}{l}\text { Implantação de um sistema de Avaliação } \\
\text { de Desempenho em uma empresa da } \\
\text { construção utilizando pesquisa ação. }\end{array}$ \\
\hline $\begin{array}{l}\text { I. M. Horta, A. S. } \\
\text { Camanho and J. M. } \\
\text { Da Costa }\end{array}$ & $\begin{array}{l}\text { Performance Assessment of Construction } \\
\text { Companies Integrating Key Performance } \\
\text { Indicators }\end{array}$ & $\begin{array}{l}\text { Analisar dados financeiros de empresas } \\
\text { da construção civil de Portugal e } \\
\text { contribuir metodologicamente na } \\
\text { avaliação da inovação. }\end{array}$ \\
\hline $\begin{array}{l}\text { S. Beatham, C. } \\
\text { Anumba, T. } \\
\text { Thorpe and I. } \\
\text { Hedges } \\
\end{array}$ & $\begin{array}{l}\text { An integrated business improvement system } \\
(I B I S) \text { for construction }\end{array}$ & $\begin{array}{l}\text { Desenvolver um sistema de avaliação de } \\
\text { desempenho baseado no EFQM }\end{array}$ \\
\hline $\begin{array}{l}\text { A. Elyamany, I. } \\
\text { Basha and T. } \\
\text { Zayed }\end{array}$ & $\begin{array}{l}\text { Performance evaluating model for } \\
\text { construction companies: Egyptian case study }\end{array}$ & $\begin{array}{l}\text { Aplica um modelo de Avaliação de } \\
\text { Desempenho baseado em dados } \\
\text { financeiros e econômicos. }\end{array}$ \\
\hline $\begin{array}{l}\text { Z. Isik, D. Arditi, I. } \\
\text { Dikmen and M. T. }\end{array}$ & $\begin{array}{l}\text { Impact of Resources and Strategies on } \\
\text { Construction Company Performance }\end{array}$ & $\begin{array}{l}\text { Criar um modelo de Avaliação de } \\
\text { Desempenho baseado em medidas }\end{array}$ \\
\hline
\end{tabular}




\begin{tabular}{|l|l|l|}
\hline Birgonul & \multicolumn{1}{|l|}{} & qualitativas. \\
\hline $\begin{array}{l}\text { C. J. Willis and J. } \\
\text { H. Rankin }\end{array}$ & $\begin{array}{l}\text { The construction industry macro maturity } \\
\text { model (CIM3): theoretical underpinnings }\end{array}$ & $\begin{array}{l}\text { Apresentar uma abordagem alternativa de } \\
\text { medir desempenho. }\end{array}$ \\
\hline
\end{tabular}

Fonte: Dados da Pesquisa (2014).

Quando aprofundada a leitura dos trabalhos, verificou-se grande dificuldade de os autores nomearem detalhadamente os indicadores-chave que devem ser utilizados para avaliar o desempenho das empresas da construção civil. Muitos apontam o que deve ser medido, porém não detalham como medir e tampouco como encontrar um número ideal para tais indicadores. Verificou-se na maioria dos estudos uma referência genérica aos indicadores não financeiros.

Outro ponto de destaque nos trabalhos estudados é a necessidade de incluir indicadores que se referem não somente ao desempenho da organização, mas também a projetos de maneira isolada. Ou seja, existe uma mescla entre indicadores da empresa e o desempenho alcançado por projeto (por obra). Esta dificuldade é inclusive citada no artigo de Yu, Ilhan, et al. (2007) “Comparable Performance Measurement System for Construction Companies”. Verificou-se que a maior lacuna encontrada nos estudos levantados se refere à dificuldade de especificar, mensurar e avaliar os indicadores de desempenho das empresas da construção civil.

Além dos estudos internacionais, foram relacionados os trabalhos nacionais ligados ao tema em questão. O processo de levantamento foi realizado em três bases de dados disponíveis na internet: portal da Capes, base Spell e Scielo.

Foi possível observar durante o procedimento de busca que a maioria dos estudos encontrados nesse processo está relacionada ao desempenho específico de alguma técnica utilizada na construção civil, como por exemplo, desempenho de um tipo de cimento, utilização de fibra de carbono, areia, gestão de resíduos, desempenho ambiental etc. Por não se tratarem de estudos relacionados ao desempenho das organizações, estes foram eliminados durante o processo de seleção. Poucos foram os estudos que tratavam da gestão do desempenho das organizações como um todo, restando somente sete trabalhos nacionais. Dentre esses estudos, nenhum deles apresentou uma proposta de avaliação de desempenho para uma pequena empresa da construção utilizando o Balanced Scorecard como ferramenta. 


\section{Metodologia}

Este trabalho é classificado como um estudo de caso, pois foi aplicado numa pequena empresa da construção civil, localizada na cidade de Florianópolis, Santa Catarina, Brasil. Esta organização foi estudada e para ela foi proposto um modelo de avaliação de desempenho, por meio da ferramenta chamada Balanced Scorecard. Para Fonseca (2002), um estudo de caso pode ser caracterizado como um estudo de uma entidade bem definida como um programa, uma instituição, um sistema educativo, uma pessoa, ou uma unidade social.

Além de um estudo de caso, este trabalho é caracterizado como uma pesquisa-ação, pois os pesquisadores e participantes representativos da situação ou do problema estão envolvidos de modo cooperativo e participativo (Gil, 2008). Foram realizadas visitas (total de quatro) com a intenção de efetuar observações in loco dos elementos organizacionais, assim como a realização de reuniões periódicas (total de seis) com os gestores para realização de entrevistas semiestruturadas, possibilitando a discussão e aprofundamento de pontos relevantes, bem como análise de documentos e relatórios disponibilizados. Dessa forma, a pesquisa ação passa a ser um processo de aprendizagem para todos os participantes, procurando diagnosticar um problema específico numa situação característica com o propósito de atingir uma relevância prática dos resultados.

As atividades foram realizadas entre os meses de outubro de 2014 e agosto de 2015, com agendamento prévio e duração média de uma hora, contando com a presença dos gestores da empresa e de um pesquisador ou dois em algumas situações. Ressalta-se aqui que os pesquisadores não possuíam vínculo de trabalho com a empresa objeto de estudo.

Este estudo, no que se refere à abordagem do problema, pode ser caracterizado como qualitativo no momento em que foram analisadas e interpretadas as variáveis da organização estudada a fim de propor o método e os indicadores ideais de avaliação de desempenho. Para Richardson e Peres (1999), a pesquisa qualitativa pode ser caracterizada como a tentativa de uma compreensão detalhada dos significados e características situacionais apresentadas pelos entrevistados, em vez de da produção de medidas quantitativas de características ou comportamentos.

Quanto aos objetivos da pesquisa, pode-se classificar como descritiva, pois foi necessário analisar os documentos da instituição, coletar dados e descrever suas características e conforme Triviños (1987) a pesquisa descritiva exige do investigador uma 
série de informações sobre o que deseja pesquisar, demandando descrever os fatos e fenômenos de determinada realidade.

Para realizar esta pesquisa foi necessário utilizar duas fontes para a coleta de dados. Fontes primárias, pois houve troca de informações com as integrantes da administração da empresa estudada, e fontes secundárias provenientes das análises de artigos de autores que realizaram trabalhos relacionados com o tema em questão. (Richardson \& Peres, 1999).

No que tange à lógica desta pesquisa, é possível enquadrá-la como indutiva - uma vez que a teoria se forma a partir da observação da realidade empírica, ou seja, vai do específico para o geral. É um processo mental por intermédio do qual, partindo de dados particulares, suficientemente constatados, infere-se uma verdade geral ou universal, não contida nas partes examinadas. (Lakatos \& Marconi, 1991). Quanto aos resultados, esta pesquisa classifica-se como aplicada, uma vez que se espera resolver um problema específico.

\section{Análise e Discussão dos Resultados}

A instituição estudada é uma pequena empresa localizada na cidade de Florianópolis, Santa Catarina. A organização é denominada como Alfa para preservar suas informações e as estratégias de negócio. A Alfa foi constituída em 2005 e atua no mercado imobiliário da Grande Florianópolis por meio da incorporação e construção de empreendimentos residenciais. Os objetivos iniciais da empresa não contemplavam nenhum público específico, os negócios eram definidos de acordo com as oportunidades que surgiam e as estratégias não eram claras. Atualmente, os imóveis construídos pela Alfa são direcionados principalmente aos clientes que se enquadram no programa Minha Casa Minha Vida e, portanto, recebem incentivos do Governo Federal para a aquisição da casa própria. Sendo assim, seu público alvo enquadra-se como classe média baixa e as estratégias da organização apresentam-se melhor definidas apesar de não formalizadas.

A primeira etapa para elaborar o BSC em uma organização é identificar sua posição no contexto atual, ou seja, a situação em que ela se encontra, seus relacionamentos e sua visão estratégica. A empresa Alfa não possuía um planejamento formal e tampouco era difundido entre os colaboradores. A sua elaboração foi realizada pelos pesquisadores juntamente com o sócio majoritário, sendo o planejamento final legitimado por ele. O Quadro 2 apresentada apresenta o Resumo do Planejamento Estratégico da empresa Alfa. 
Construção de um modelo de avaliação de desempenho: estudo de caso em uma empresa de pequeno porte da construção civil

Quadro 2 - Resumo Planejamento Estratégico empresa Alfa.

\begin{tabular}{|c|c|c|}
\hline Negócio & \multicolumn{2}{|l|}{ Construir e incorporar edificações residenciais. } \\
\hline Missão & \multicolumn{2}{|c|}{$\begin{array}{l}\text { Conceber, construir e entregar empreendimentos de qualidade, com responsabilidade } \\
\text { ambiental e preço justo para promover a realização de sonhos. }\end{array}$} \\
\hline Visão & \multicolumn{2}{|c|}{$\begin{array}{l}\text { Ser uma empresa da construção civil reconhecida na região, até } 2016 \text {, pela qualidade de seus } \\
\text { produtos, seriedade, confiança e respeito com o cliente, desenvolvendo empreendimentos } \\
\text { com alto potencial de retorno por meio de atitudes inteligentes e sustentáveis. }\end{array}$} \\
\hline Valores & \multicolumn{2}{|c|}{ Respeito com o cliente; responsabilidade ambiental; confiabilidade; foco no resultado. } \\
\hline \multirow[b]{2}{*}{ 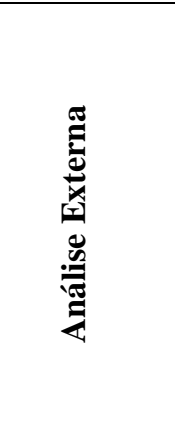 } & Oportunidades & Ameaças \\
\hline & $\begin{array}{l}\text { Ascensão da classe C e D. } \\
\text { Políticas governamentais de incentivo à } \\
\text { casa própria. } \\
\text { Aumento no crédito imobiliário. } \\
\text { Crescimento do mercado imobiliário na } \\
\text { Grande Florianópolis. } \\
\text { Déficit imobiliário brasileiro. }\end{array}$ & $\begin{array}{l}\text { Mudanças nas políticas governamentais de } \\
\text { incentivo à casa própria. } \\
\text { Crise econômica nacional e regional. } \\
\text { Crescimento de oferta pelo aumento de } \\
\text { concorrentes diretos. } \\
\text { Excesso de burocracia para obtenção de } \\
\text { recursos. } \\
\text { Dificuldade para captação de mão de obra. }\end{array}$ \\
\hline \multirow[b]{2}{*}{ 总 } & Pontos Fortes & Pontos Fracos \\
\hline & $\begin{array}{l}\text { Estrutura de custos enxuta. } \\
\text { Produtos com preços acessíveis. } \\
\text { Equipe qualificada e de confiança. } \\
\text { Agilidade em reagir às mudanças de } \\
\text { mercado. } \\
\text { Gestão financeira sustentável. } \\
\text { Produtos que atendem as necessidades } \\
\text { dos clientes. }\end{array}$ & $\begin{array}{l}\text { Ausência de política de qualidade bem definida. } \\
\text { Falta de acompanhamento pós-venda. } \\
\text { Lentidão na tomada de decisão por acúmulo de } \\
\text { funções. } \\
\text { Limitação de crescimento. }\end{array}$ \\
\hline $\begin{array}{l}\text { Fatores } \\
\text { Críticos de } \\
\text { Sucesso }\end{array}$ & \multicolumn{2}{|c|}{$\begin{array}{l}\text { Programas governamentais - Minha casa Minha Vida. } \\
\text { Mão de obra própria e qualificada. }\end{array}$} \\
\hline
\end{tabular}

Fonte: Dados da Pesquisa (2015).

Durante o processo de elaboração do Planejamento Estratégico, foi necessário definir as políticas estratégicas da organização, ou seja, identificar os caminhos que a empresa deverá seguir para garantir a competitividade e sobrevivência no longo prazo. A empresa Alfa apresenta as seguintes políticas estratégias: 1) garantir alto potencial de retorno em seus negócios, pois o fato de os administradores apresentarem uma postura conservadora e optarem por trabalhar sempre com capital próprio torna a empresa Alfa dependente de seus recursos financeiros, limitando a quantidade de empreendimentos a serem construídos. Dessa forma, a empresa não consegue ganhar no giro e sim na margem de seus negócios. Sendo assim, os administradores precisam estudar cuidadosamente seus projetos para tentarem maximizar o 
retorno de seus empreendimentos. Além do estudo por obra, a empresa necessita de controlar seus custos e despesas fixas e variáveis de modo a garantir o alto potencial de retorno da organização. Conseguir garantir esse potencial torna-se o principal atrativo para os sócios administradores da empresa que ao analisarem o custo de oportunidade das possíveis fontes de renda em suas profissões, optam por preservar e progredir na administração da empresa Alfa; 2) fortalecer a confiança da organização perante os clientes, pois o aumento da concorrência e das ofertas por produtos similares trouxe recuo nas vendas dos imóveis na Grande Florianópolis, causando desaquecimento ao mercado imobiliário. A desaceleração do setor apresentada também sofreu influência da retração econômica nacional e contribuiu para assomar a competição do setor. Sendo assim, o que era pouco trabalhado e investido na empresa Alfa, ou seja, a preocupação direta com a satisfação dos clientes passa a ser repensada e torna-se uma política determinante para o atingimento das estratégias da organização; 3) atitudes inteligentes e sustentáveis, pois agir de maneira sustentável está diretamente ligado à capacidade da organização em atuar de forma a não esgotar os recursos necessários para o bom desempenho da empresa. O termo sustentável neste caso, não está direcionado apenas para questões ambientais, mas sim para todas as atitudes tomadas na organização. Os administradores entendem que para garantir o retorno esperado, as práticas dentro da Alfa precisam ser estudadas e analisadas cuidadosamente de forma a evitar desperdícios, retrabalho e perda de recursos. Como exemplo é possível citar a utilização do dinheiro disponível em caixa, escolha de novos investimentos, negociação com clientes e fornecedores, relacionamento com colaboradores, práticas de aproveitamento de recursos naturais como água e energia solar, definição de processos internos, boas contratações, entre outros.

As políticas estratégias apresentadas embasarão e originarão os objetivos e ações estratégicas desenvolvidas para cada uma das perspectivas propostas pela metodologia do Balanced Scorecard. A seguir será apresentado o modelo de avaliação de desempenho construído para a empresa Alfa de acordo com o planejamento aqui exposto.

\section{O mapa estratégico}

O mapa estratégico é um instrumento utilizado para facilitar a compreensão pelos gestores dos processos complexos que eles se deparam diariamente evitando que se percam 
diante de inúmeras informações. É por meio dele que é realizado o monitoramento do cumprimento da estratégia da organização, sendo disposto nas quatro perspectivas de gestão: Aprendizado e Crescimento, Processos Internos, Clientes e Financeira. Dessa forma, essa ferramenta necessita de ser consistente, específica, organizada por objetivos estratégicos e sucinta. (Costa, A.P. 2006). A Figura 1 apresenta o Mapa Estratégico proposto para a empresa Alfa.

Figura 1: Mapa estratégico proposto.

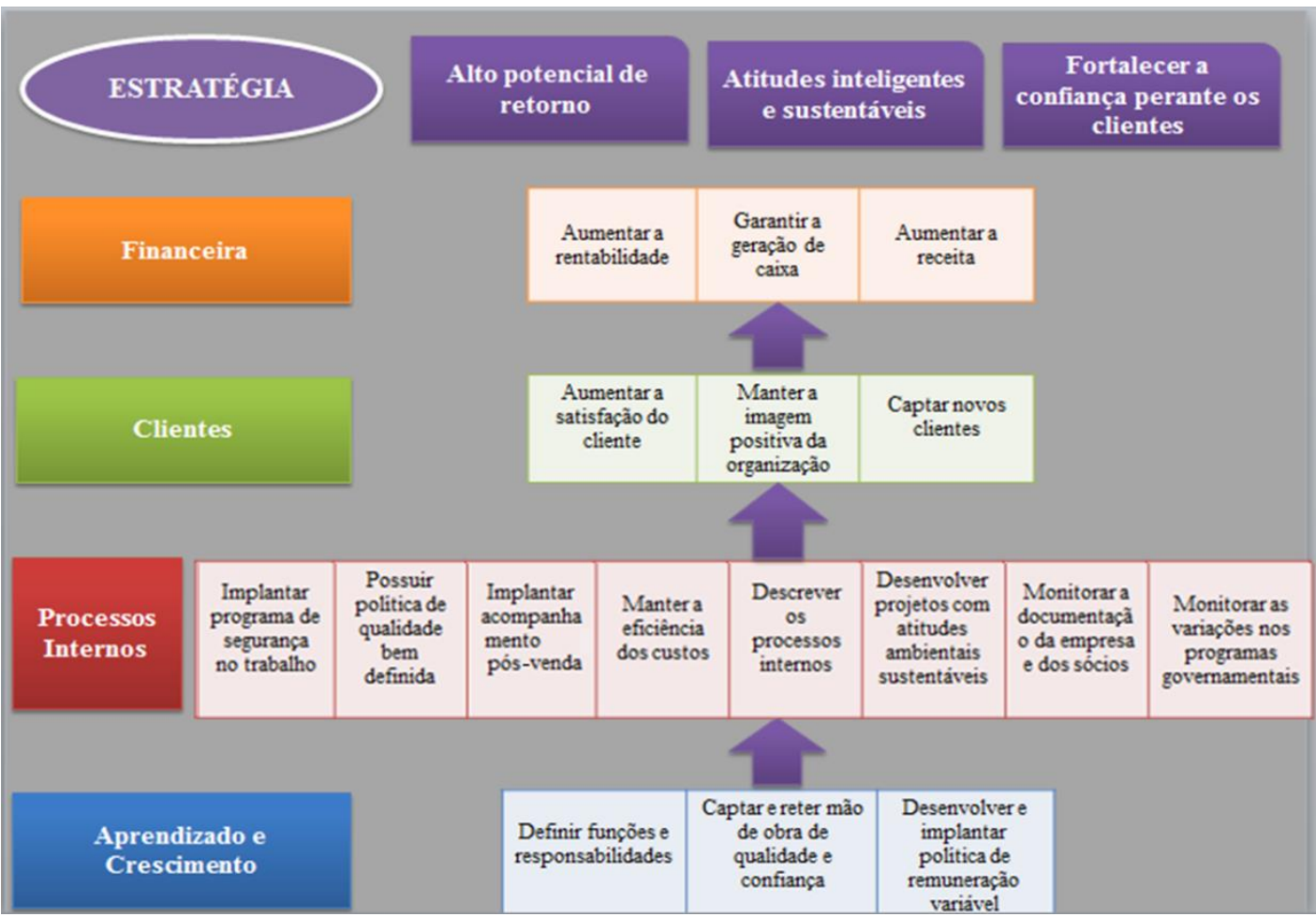

Fonte: Elaborado pelos autores (2015).

O mapa estratégico apresentado ilustra a relação de causa e efeito conectando os resultados almejados para cada perspectiva (Kaplan e Norton, 1997). As setas do mapa estratégico indicam esta relação de causa e efeito, uma vez que as ações estão dispostas em relação de cadeia a fim de alcançar os objetivos predeterminados pela estratégia.

\section{Painel de indicadores de desempenho}

O painel de indicadores é a composição de um conjunto de medidas consideradas chave para avaliar o cumprimento dos objetivos estratégicos. Tais medidas, que não necessitam ser 
inúmeras, darão a indicação do desempenho da organização diante dos objetivos almejados. De acordo com Costa, A. P. (2006), com um reduzido número de medidas, os gestores e colaboradores podem focar a estratégia, chamando atenção para os fatores esperados para a mudança de desempenho desejada, ao invés de se perderem na diversidade de indicadores.

É por meio do painel de indicadores que a organização conseguirá definir como o desempenho será medido e monitorado. Uma vez definidos os objetivos que precisam ser alcançados para cumprir a estratégia, deve-se identificar a forma de acompanhar o resultado do esforço em alcançá-los (Costa, 2006).

Os indicadores propostos à empresa Alfa obedecem à ordem de serem facilmente compreendidos e calculados. Entende-se que quanto mais complexo for o indicador, mais difícil de os membros da organização compreendê-los e, portanto, executá-los e controlá-los.

Os indicadores serão apresentados para cada objetivo de cada perspectiva. Além de apresentados, evidenciar-se-á como cada um deles deverá ser calculado, e as iniciativas que devem ser realizadas para garantir o atendimento das metas, facilitando assim a compreensão e os motivos da existência de cada indicador. As iniciativas propostas constarão nas perspectivas de Aprendizado e Crescimento e de Processos Internos, visto que as consequências destas iniciativas refletirão no atingimento das metas traçadas pelas perspectivas de Cliente e Financeira. O prazo proposto para que as metas sejam alcançadas e posteriormente revistas é de dois anos.

Os indicadores que não puderam ser encontrados por falta de informação da organização, receberão a classificação de N. D., significando que não foi desenvolvido.

\section{Perspectiva de aprendizado e crescimento}

A finalidade da Perspectiva de Aprendizado e Crescimento é investir primordialmente na reciclagem e qualificação de seus trabalhadores e gestores, bem como na melhoria dos sistemas de informação e alinhamento dos procedimentos da empresa (Kaplan \& Norton, 1997). No Quadro 3 serão apresentados os objetivos, indicadores, metas e iniciativas propostos a essa perspectiva para a empresa Alfa. 
Construção de um modelo de avaliação de desempenho: estudo de caso em uma empresa de pequeno porte da construção civil

Quadro 3: Painel de desempenho pela perspectiva aprendizado e crescimento.

\begin{tabular}{|c|c|c|c|c|}
\hline Objetivo & Indicador & $\begin{array}{c}\text { Status } \\
\text { atual }\end{array}$ & Meta & Iniciativas \\
\hline $\begin{array}{l}\text { Definir funções e } \\
\text { responsabilidades }\end{array}$ & $\begin{array}{l}\text { (Descrições de cargos } \\
\text { validadas / Número total } \\
\text { de cargos) } * 100\end{array}$ & N.D. & $100 \%$ & $\begin{array}{l}\text { - Levantar as funções e cargos existentes. } \\
\text { - Desenhar o organograma. } \\
\text { - Descrever missão, atividades, } \\
\text { responsabilidades, conhecimento técnico } \\
\text { e habilidades exigidas em cada cargo. } \\
\text { - Divulgar e treinar os colaboradores. }\end{array}$ \\
\hline \multirow{3}{*}{$\begin{array}{l}\text { Captar e reter mão } \\
\text { de obra de } \\
\text { qualidade e } \\
\text { confiança }\end{array}$} & $\begin{array}{l}\{[(\text { admissões+demissões }) / \\
2] / \text { efetivo médio }\} * 100\end{array}$ & $50 \%$ & $30 \%$ & \multirow{3}{*}{$\begin{array}{l}\text { - Programa de segurança no trabalho. } \\
\text { - Remuneração variável. } \\
\text { - Clareza nas descrições das } \\
\text { responsabilidades. } \\
\text { - Gestão de Recursos Humanos. }\end{array}$} \\
\hline & $\begin{array}{l}\% \text { de colaboradores com } \\
\text { perfil desejado }\end{array}$ & N. D. & $80 \%$ & \\
\hline & $\begin{array}{ll}\% \text { de respostas que o } \\
\text { colaborador está no } \\
\text { mínimo satisfeito } \\
\end{array}$ & N. D. & $70 \%$ & \\
\hline $\begin{array}{c}\text { Desenvolver e } \\
\text { Implantar Política } \\
\text { de Remuneração } \\
\text { Variável }\end{array}$ & $\begin{array}{l}\text { (número de metas } \\
\text { atingidas/ } \\
\text { número de metas traçadas) } \\
* 100\end{array}$ & N. D. & $80 \%$ & $\begin{array}{l}\text { - Identificar os pontos críticos de sucesso } \\
\text { por área. } \\
\text { - Estipular metas. } \\
\text { - Desenvolver os parâmetros de } \\
\text { remuneração varável. } \\
\text { - Comunicar e motivar a equipe. } \\
\end{array}$ \\
\hline
\end{tabular}

Fonte: Elaborado pelos autores (2015).

Os objetivos e iniciativas aqui apresentados envolvem as pessoas, os sistemas e os procedimentos organizacionais que formam as principais fontes para esta perspectiva. A proposta é oferecer uma infraestrutura necessária para a realização dos objetivos das demais perspectivas.

\section{Perspectiva dos processos internos}

A Perspectiva dos Processos Internos contempla a identificação dos recursos e das capacidades necessárias para elevar o nível interno de qualidade da organização. Esta perspectiva, apresentada no Quadro 4, considera o processo de inovação, operações e pósvenda.

Quadro 4 - Painel de desempenho pela perspectiva de processos internos.

\begin{tabular}{|l|l|c|c|l|}
\hline \multicolumn{1}{|c|}{ Objetivo } & \multicolumn{1}{|c|}{ Indicador } & $\begin{array}{c}\text { Status } \\
\text { atual }\end{array}$ & Meta & \multicolumn{1}{|c|}{ Iniciativas } \\
\hline $\begin{array}{l}\text { Implantar } \\
\text { programa de } \\
\text { segurança no } \\
\text { trabalho }\end{array}$ & $\begin{array}{l}\text { Número de acidentes de } \\
\text { trabalho por obra. }\end{array}$ & 10 & 5 & $\begin{array}{l}\text { - Treinamento e conscientização dos } \\
\text { colaboradores. } \\
\text { - Monitoramento das práticas } \\
\text { preventivas e dos acidentes de trabalho. }\end{array}$ \\
\cline { 2 - 4 } & $\begin{array}{l}\text { (Acidentes Graves / Total de } \\
\text { Acidentes }) * 100\end{array}$ & 1 & Zero \\
\hline
\end{tabular}




\begin{tabular}{|c|c|c|c|c|}
\hline $\begin{array}{l}\text { Possuir uma } \\
\text { política de } \\
\text { qualidade bem } \\
\text { definida }\end{array}$ & $\begin{array}{l}\text { Número de não } \\
\text { conformidades }\end{array}$ & 5 & 2 & $\begin{array}{l}\text { - Desenvolver a Política de Qualidade. } \\
\text { - Nomear responsáveis pelo controle e } \\
\text { acompanhamento das não } \\
\text { conformidades. }\end{array}$ \\
\hline \multirow{2}{*}{$\begin{array}{l}\text { Implantar } \\
\text { acompanhamento } \\
\text { pós-venda }\end{array}$} & $\begin{array}{l}\text { Prazo de retorno das } \\
\text { reclamações. }\end{array}$ & N.D. & $24 \mathrm{~h}$ & \multirow{2}{*}{$\begin{array}{l}\text { - Definir a forma de acompanhamento } \\
\text { do pós-venda. } \\
\text { - Nomear e treinar colaborador } \\
\text { responsável. }\end{array}$} \\
\hline & $\begin{array}{l}\text { Número de reclamações por } \\
\text { imóvel vendido. }\end{array}$ & 3 & 1 & \\
\hline \multirow{2}{*}{$\begin{array}{l}\text { Manter a } \\
\text { eficiência dos } \\
\text { custos }\end{array}$} & $\begin{array}{l}\text { (Gastos fixos / Receita média } \\
\text { mensal) } * 100\end{array}$ & $5 \%$ & $5 \%$ & \multirow{2}{*}{$\begin{array}{l}\text { - Manter o controle dos gastos fixos. } \\
\text { - Aprimorar a negociação com } \\
\text { fornecedores. }\end{array}$} \\
\hline & $\begin{array}{l}\text { (Desvio do Custo da obra / } \\
\text { Custo da obra orçado) *100 }\end{array}$ & $6 \%$ & $6 \%$ & \\
\hline $\begin{array}{l}\text { Descrever os } \\
\text { processos } \\
\text { internos }\end{array}$ & $\begin{array}{l}\left(\mathrm{n}^{\circ} \text { de processos descritos e }\right. \\
\text { validados } / \mathrm{n}^{\circ} \text { de processos a } \\
\text { descrever }) * 100\end{array}$ & N.D. & $40 \%$ & $\begin{array}{l}\text { - Levantar o número de processos a } \\
\text { serem descritos. } \\
\text { - Descrever os processos junto com os } \\
\text { envolvidos. } \\
\text { - Validar e divulgar os processos. }\end{array}$ \\
\hline \multirow{2}{*}{$\begin{array}{l}\text { Desenvolver } \\
\text { projetos com } \\
\text { atitudes } \\
\text { ambientais } \\
\text { sustentáveis }\end{array}$} & $\begin{array}{l}\text { Número de caçambas de } \\
\text { entulho por obra }\end{array}$ & Zero & Zero & \multirow{2}{*}{$\begin{array}{l}\text { - Manter o controle de resíduos. } \\
\text { - Desenvolver atitudes de baixo custo } \\
\text { voltadas para a preservação ambiental. }\end{array}$} \\
\hline & $\begin{array}{l}\text { Número de estruturas } \\
\text { deixadas por obra }\end{array}$ & 2 & 2 & \\
\hline $\begin{array}{l}\text { Monitorar a } \\
\text { documentação da } \\
\text { empresa e sócios }\end{array}$ & $\begin{array}{l}\text { Número de atrasos dos } \\
\text { processos em função da falta } \\
\text { de documentação }\end{array}$ & 2 & Zero & $\begin{array}{l}\text { - Nomear e treinar colaboradores } \\
\text { responsáveis pelo controle da } \\
\text { documentação. }\end{array}$ \\
\hline $\begin{array}{l}\text { Monitorar e } \\
\text { acompanhar } \\
\text { variações nos } \\
\text { programas } \\
\text { governamentais }\end{array}$ & $\begin{array}{l}\text { Total de programas } \\
\text { governamentais aproveitados }\end{array}$ & 1 & 1 & $\begin{array}{l}\text { - Nomear e treinar colaboradores } \\
\text { responsáveis pelo monitoramento e } \\
\text { especulação de mercado. }\end{array}$ \\
\hline
\end{tabular}

Fonte: Elaborado pelos autores (2015).

Com a execução das iniciativas propostas pelas Perspectivas de Aprendizado e Crescimento e Processos Internos, espera-se, como consequência, atingir as metas traças nas Perspectivas de Clientes e Financeira conforme a seguir.

\section{Perspectiva de clientes}

A Perspectiva dos Clientes busca identificar os fatores que realmente importam aos consumidores, ou seja, os principais atributos dos serviços/produtos, o relacionamento que a empresa possui para com seus clientes, imagem e reputação da organização diante dos consumidores e da sociedade. 
Construção de um modelo de avaliação de desempenho: estudo de caso em uma empresa de pequeno porte da construção civil

Quadro 5 - Painel de desempenho pela perspectiva de clientes.

\begin{tabular}{|l|l|l|l|}
\hline \multicolumn{1}{|c|}{ Objetivo } & \multicolumn{1}{|c|}{ Indicador } & \multicolumn{1}{c|}{ Status atual } & Meta \\
\hline Aumentar a satisfação do cliente & Índice de satisfação do cliente & N. D. & $80 \%$ \\
\hline $\begin{array}{l}\text { Manter a imagem positiva da } \\
\text { organização }\end{array}$ & $\begin{array}{l}\text { (Entrevistados que possuem imagem positiva } \\
\text { da organização/ Total de entrevistados) } * 100\end{array}$ & N. D. & $80 \%$ \\
\hline Captar/Atrair novos clientes & $\begin{array}{l}\text { (Número de clientes novos atraídos pela } \\
\text { captação/ Total de clientes) } * 100\end{array}$ & N. D. & $30 \%$ \\
\hline
\end{tabular}

Fonte: Elaborado pelos autores (2015).

A empresa Alfa nunca se preocupou com indicadores relacionados aos clientes em função da grande procura e pelo o aquecimento do mercado nos últimos anos. Entretanto, a atual instabilidade econômica e política do país fazem com que as atitudes dos sócios sejam repensadas a adaptadas à nova realidade.

\section{Perspectiva financeira}

A perspectiva financeira indica os resultados tangíveis da organização, expressando se a empresa está obtendo êxito com as estratégias definidas, implementadas e executadas. A proposta para a empresa Alfa é apresentada no Quadro 6.

Quadro 6 - Painel de desempenho pela perspectiva financeira.

\begin{tabular}{|c|l|c|c|}
\hline \multicolumn{1}{|c|}{ Objetivo } & \multicolumn{1}{|c|}{ Indicador } & Status atual & Meta \\
\hline Aumentar a rentabilidade & (Lucro Líquido / Capital investido) $* 100$ & $27 \%$ & $30 \%$ \\
\hline \multirow{2}{*}{\begin{tabular}{c} 
Garantir a geração de $\begin{array}{c}\text { caixa } \\
\text { caixa }\end{array}$ \\
\cline { 2 - 4 }
\end{tabular}} & EBITDA & $40 \%$ & $40 \%$ \\
\cline { 2 - 4 } & Total de pagamentos atrasados & 0 & 0 \\
\hline Aumentar a receita & (Variação da receita / Receita do período anterior) $* 100$ & $15 \%$ & $20 \%$ \\
\hline
\end{tabular}

Fonte: Elaborado pelos autores (2015).

Diante dos resultados apresentados, ao compará-los com aqueles relatados nas pesquisas similares, é possível concluir que apesar de os estudos contribuírem de diversas formas para o tema de avaliação de desempenho na construção civil, nenhum, no levantamento realizado, aborda o assunto de maneira completa, ou seja, não iniciam pelas estratégias da empresa e finalizam com a elaboração dos indicadores, suas metas e iniciativas. Apesar de algumas 
pesquisas relacionarem os indicadores de desempenho e suas respectivas fórmulas, os trabalhos apresentam conclusões mais genéricas e muitas vezes comparativas.

Sendo assim, este estudo é considerado um diferencial por elaborar uma proposta completa, utilizando uma ferramenta reconhecida no mercado e na literatura e por apresentar indicadores de fácil compreensão e controle, voltados para uma pequena empresa do setor.

\section{Considerações Finais}

Os números apresentados ao longo desta pesquisa evidenciaram a importância do setor para geração de empregos, arrecadação de impostos, inclusão social, absorção de mão de obra, participação no PIB, entre outros fatores que contribuem para o desenvolvimento do Brasil. Na revisão teórica constatou-se que a parcela significativa de pequenas empresas e as peculiaridades deste setor foram fatores que motivaram este estudo principalmente pela escassez de trabalhos nacionais e internacionais similares.

A informalidade e o amadorismo pelo qual as pequenas empresas da construção civil são administradas evidenciaram uma necessidade de formalização e melhor controle para que os objetivos estratégicos das organizações fossem alcançados - o que as chances de sobrevivência destas empresas diante da concorrência e das crises econômicas. Avaliar e monitorar o desempenho dessas empresas é uma das maneiras de garantir a continuidade competitiva, pois gera conhecimento necessário para auxiliar nos processos decisórios da organização.

Diante de uma série de ferramentas de gestão voltadas para avaliação de desempenho, este estudo se propôs a utilizar o Balanced Scorecard em função de seu destaque na literatura, por ser a ferramenta mais utilizada por gestores na Europa no ano de 2013, por preencher a lacuna existente nos demais sistemas gerenciais e possibilitar, assim, um processo sistemático para implementar e obter feedback sobre a estratégia. Este sistema, que tem foco na visão da empresa, trabalha com quatro perspectivas, as de aprendizado e crescimento, processos internos, clientes e financeira, e pode ser utilizado nas organizações de qualquer porte. Para cada perspectiva proposta foram identificados os objetivos, os indicadores, as metas e as iniciativas para que as metas sejam contempladas. A facilidade na visualização do sistema é também um motivo pelo qual foi proposto o uso de tal ferramenta. 
Sendo assim, este estudo foi elaborado com o propósito de demonstrar como avaliar o desempenho de uma organização de pequeno porte do ramo da construção civil, e dessa forma auxiliar no processo de melhoria e de gestão da organização.

Para contemplar os objetivos propostos, juntamente com os administradores, foi apresentado primeiramente o planejamento estratégico da instituição que serviu como base para a proposta do modelo de avaliação de desempenho. Em seguida, dando início à utilização do BSC, foi elaborado o mapa estratégico onde foram apresentados os objetivos necessários para o cumprimento da estratégia baseado no planejamento da organização. O mapa evidenciou a ligação existente entre as perspectivas e os relacionamentos de causa e efeito entre as ações e a estratégia da empresa. Por meio deste mapa os gestores poderão visualizar e monitorar o desempenho da organização.

Dando continuidade à recomendação, para cada objetivo traçado foram criados indicadores capazes de mensurar se os objetivos estão sendo contemplados. Vale destacar a importância de os indicadores serem simples, objetivos e de fácil compreensão para que os gestores assimilem com maior clareza as informações contidas no painel. O número reduzido de colaboradores exige acúmulo de funções e, portanto, quanto mais prático e mais simples for, melhores serão os resultados contemplados pelo sistema de gestão.

A etapa seguinte da pesquisa foi identificar a situação atual da empresa para cada indicador criado e, juntamente com os administradores, traçar as metas a serem contempladas. A meta é a quantificação do desempenho desejado a ser medido. Nesta fase, por falta de controle da instituição, muitos indicadores não puderam ser mensurados, não havendo levantamento da situação atual. Assim, as metas traçadas foram baseadas no conhecimento e na experiência dos administradores, que poderão revisá-las quando necessário. Vale salientar que o BSC centraliza sua atenção na estratégia, na visão e não no controle operacional, ou seja, as medidas foram estabelecidas para que os membros pudessem conduzir seus trabalhos em direção à visão geral, à estratégia.

Por fim, para cada indicador proposto foram sugeridas ações que pudessem contribuir para o cumprimento das metas apresentadas. Para garantir que as metas sejam alcançadas, nenhuma pode ficar sem plano de ação.

Diante do exposto é possível afirmar que os objetivos gerais e específicos desta pesquisa foram contemplados no sentido de construir um modelo de avaliação de desempenho para uma empresa de pequeno porte do ramo da construção civil. Vale destacar que o BSC 
não é uma "receita de bolo", ou seja, não é uma ferramenta engessada que pode ser utilizada em qualquer instituição. Por ser baseado principalmente na estratégia e na visão da empresa, seu modelo sofre variações de acordo com os objetivos de cada instituição.

A partir da proposta elaborada, os administradores necessitam de comunicar a todos os envolvidos na operação da empresa para alinhar a organização à estratégia, atribuir responsabilidades e assim tornar a estratégia um processo contínuo de forma a mobilizar as mudanças necessárias na equipe.

O Balanced Scorecard é uma ferramenta que não traz conceitos novos, nunca tratados na literatura, porém repensa temas antigos que estavam mal compreendidos ou até mesmo esquecidos. Essa ferramenta ajuda a empresa a organizar seus passos com o propósito de cumprir as estratégias traçadas. Esse sistema de gestão obriga os administradores a repensarem suas táticas e avaliarem a validade de seus controles e de planejamento.

Entende-se que a aplicação dessa ferramenta irá reformular as atitudes dos membros da empresa Alfa, de forma que as atividades, as responsabilidades, os controles e principalmente a estratégia da organização sejam evidenciadas com maior clareza fazendo com que os gestores reflitam sobre o negócio de forma organizada e sistêmica.

Durante o processo de elaboração desta pesquisa, foram relacionadas algumas limitações como a falta de dados da empresa estudada e a inexistência de alguns controles que dificultaram a elaboração das metas e de algumas iniciativas, a comparação de estudos semelhantes que se limita ao levantamento dos estudos encontrados pela pesquisa bibliométrica realizada pelo pesquisador, a impossibilidade de testar a proposta do modelo na empresa estudada, o fato de o modelo proposto ser aplicado somente na organização estudada, não podendo ser replicado a outras instituições sem as devidas adaptações e por fim, o estudo não apresentar a mensuração dos custos com a implantação da proposta.

O desenvolvimento deste estudo estimula a exploração de alguns assuntos que não puderam ser desenvolvidos e aprofundados nesta pesquisa. Dessa forma, recomenda-se para trabalhos futuros desenvolver estudos semelhantes em pequenas empresas da construção civil utilizando outras ferramentas de gestão, desenvolver uma pesquisa com o objetivo de colocar em prática a proposta do BSC na empresa Alfa, desenvolver pesquisa semelhante, porém em grandes empresas da construção civil e realizar um estudo que relacione as dificuldades dos gestores em aplicar o BSC nas empresas da construção civil. 


\section{Referências}

Agência Brasileira de Desenvolvimento Industrial - ABDI (2009). Estudo panorama setorial de construção civil. Recuperado em 25 de setembro, 2014 de $<$ http://www.abdi.com.br>.

Breitbach, A. C. M. Indústria da construção civil: a retomada (2009). Revista Indicadores.

Câmara Brasileira da Indústria da Construção - CBIC. (2014). A produtividade da construção civil brasileira. Recuperado em 25 de maio, 2014 de <http://www.cbicdados.com.br〉.

Costa, A. P. P. da (2006). Balanced Scorecard: conceitos e guia de implementação. São Paulo: Atlas.

Costa, D. B. ., Formoso, C. T., Kagioglou, M., Alarcón, L. F., \& Caldas, C. H. (2006). Benchmarking initiatives in the construction industry: lessons learned and improvement opportunities. Journal of Management in Engineering, 22.4: 158-167.

Costa, D. B. (2003) Diretrizes para concepção, implantação e uso de sistemas de indicadores de desempenho para empresas da construção civil. Dissertação (Mestrado em Engenharia Civil), Universidade Federal do Rio Grande do Sul.

Fonseca, J. J. S. (2002). Metodologia da Pesquisa Científica. Apostila.

Galvão, H. M., Corrêa, H. L. \& Alves, J. L. (2011). Modelo de avaliação de desempenho global para instituição de ensino superior. Revista de Administração da UFSM, vol. 4, n. 3, pp. 425-441, 2011.

Gil, A. C. (2008). Métodos e técnicas de pesquisa social (6a. ed.). São Paulo: Editora Atlas.

Kaplan, R. S. \& Norton, D. P. (1997). A estratégia em ação: balanced scorecard. Gulf Professional Publishing.

Kraemer, M. E. P. (2009). O balanced scorecard e seu impacto na contabilidade gerencial. Contabilidade Vista \& Revista, 13(3), 53-70.

Lakatos, E. M. \& Marconi, M. de A. (1991). Metodologia científica. São Paulo: Atlas.

Meseguer, A. G. (1991). Controle e garantia da qualidade na construção. Sindicato da Indústria da Construção Civil de Grandes Estruturas no Estado de São Paulo. 
Moraes, S. M. D. S. D. (2009). Estratégias competitivas adotadas na construção civil brasileira: uma análise das empresas líderes do setor. Monografia em Economia, Universidade Federal de Santa Catarina, Florianópolis.

Petri, S. M. (2005). Modelo para apoiar a avaliação das abordagens de gestão de desempenho e sugerir aperfeiçoamento: sob a ótica construtivista. Tese de Doutorado em Engenharia da Produção, Universidade Federal de Santa Catarina, Florianópolis.

Richardson, R. J. \& Peres, J. A. de S. (1999). Pesquisa social: métodos e técnicas. São Paulo: Atlas.

Rigby, D. \& Bilodeau, B. (2013). Management tools \& trends. Boston, MA: Bain \& Company.

Teixeira, L. P. \& Carvalho, F. M. A. de (2005). A construção civil como instrumento do desenvolvimento da economia brasileira. Revista Paranaense de Desenvolvimento, (109), 9-26.

Triviños, A. N. S. (1987) Introdução à pesquisa em ciências sociais: a pesquisa qualitativa em educação. São Paulo: Atlas.

Yamauchi, V. (2003). A gestão do conhecimento e a inovação organizacional na construção civil, 2003. Dissertação de mestrado em Construção Civil, do Programa de Pósgraduação em Construção Civil, Setor de Tecnologia, Universidade Federal do Paraná, Curitiba, PR, Brasil).

Yu, I. et al. (2007) Comparable performance measurement system for construction companies. Journal of Management in Engineering, vol. 23, n. 3, pp. 131-139. 